\title{
DISCIPLINA E CONTROLE: LIAMES, DISTANCIAMENTOS, QUESTÕES
}

\author{
DISCIPLINE AND CONTROL: BONDS, DISTANCES, QUESTIONS
}

Felipe Sampaio de Freitas*

https://orcid.org/0000-0001-9071-0652

http://lattes.cnpq.br/5536983747166169

\section{Flávia Cristina Silveira Lemos** \\ http://orcid.org/0000-0002-6601-0653 http://lattes.cnpq.br/8132595498104759}

Recebido em: 7 de abril de 2020

Aprovado em: 20 de julho de 2020

RESUMO: O artigo propõe a problematização de alguns importantes termos que estão presentes no trajeto filosófico de Michel Foucault e Gilles Deleuze, no período que se enquadra em meados dos anos setenta, no caso do primeiro; e, no início dos anos noventa, no caso do último. São eles: a noção de poder disciplinar, poder soberano; e sociedades de controle. O intuito disto é não apenas entendê-los, mas assinalar ao leitor como estão, de certa maneira, intrínsecos; apontando também seus eventuais distanciamentos, para, acima de tudo, provocá-lo a uma crítica contemporânea do capital. Nossa metodologia inclui, basicamente, a utilização de obras e cursos de Michel Foucault e Gilles Deleuze, bem como da investigação de alguns de seus principais comentadores.

Palavras-chave: Soberania; Disciplina; Poder; Controle; Modulação.

\begin{abstract}
This paper proposes problematization of some important terms that are present in the philosophical trajectory of Michel Foucault and Gilles Deleuze, in the period that falls in the mid-seventies, in the case of the first; and, in the early nineties, in the case of the latter. They are: the notion of disciplinary power, sovereign power, and control societies. The purpose of this is not only to understand them, but to point out to the reader how they are, in a way, intrinsic, also pointing out their possible distances, in order, above all, to provoke him to a contemporary critique of capital. Our methodology basically includes the use of works and courses by Michel Foucault and Gilles Deleuze, as well as the investigation of some of its main commentators.
\end{abstract}

Key-words: Sovereign; Discipline; Power; Control; Modulation.

\footnotetext{
* Licenciado (FAFIL-IFCH-UFPA) e mestre em filosofia pelo PPGFIL-UFPA. Doutorando em Psicologia Social pelo PPGP-UFPA. Professor da disciplina filosofia, do Ensino Fundamental II ao Ensino Médio, no Colégio Modelo/PA. E-mail: felipesampaiodefreitas@gmail.com.

** Professora pesquisadora do curso de Psicologia e do Programa de Pós-Graduação em Psicologia da Universidade Federal do Pará. Belém. E-mail: flaviacslemos@gmail.com.
} 


\section{INTRODUÇÃO}

Neste artigo, investigaremos os desdobramentos das investidas teóricas acerca do tema do poder disciplinar (pouvoir disciplinaire), presente na obra de Michel Foucault. No entanto, sem nos propormos à exaustiva tarefa de mapeá-lo. O poder disciplinar se caracteriza por meio de práticas em sua relação intrínseca com o saber. Estes últimos, não mais estando pura e simplesmente circunscritos ao nível do discurso (como operado pelo mesmo na década de sessenta), mas localizados no registro do não-discursivo, logo, da "passagem para as práticas culturais [...] que reuniam poder-saber" (RABINOW e DREYFUS, 1995, p. 202); utilizaremos exemplos de práticas disciplinares referentes aos períodos históricos, os quais Foucault utilizou para realizar seus estudos, quando de sua atividade no Collège de France, nos anos 1970, como forma de ilustração. Feito isso, analisaremos no que consiste a passagem da sociedade da disciplina para a sociedade do controle. Esta última, delimitada em 1990, pelo filósofo francês e amigo de Foucault, Gilles Deleuze. O intuito é o de cotejar até que ponto as noções se distanciam, ou se aproximam, averiguando seus níveis de veridicção na sociedade atual. Almejamos, adjunto a isso, uma crítica contemporânea do capital e do consumo.

Lembremos de antemão que a dualidade entre discursivo e o não-discursivo se deve à inserção, feita por Foucault, da noção de dispositivo, em sua obra, principalmente a partir da chamada "fase genealógica" (um eixo mais complexo que "reúne o discursivo e o extradiscursivo”) (MUCHAIL, 2004, p. 60), ou seja, uma função estratégica que permite articulações de produção de saber com modos de exercício de poder. Quesito igualmente importante é o de lembrar que este ato de Foucault, ora, de "se debruçar" sobre questões acerca poder, não anuncia que o mesmo pretenda cunhar uma teoria "acontextual, a-histórica" (RABINOW e DREYFUS, 1995, p. 202), que verse de maneira ontológica sobre os sujeitos. Por isso, ele sugere que a análise das relações de poder é uma analítica, atentando ao âmbito prático.

\section{FOUCAULT, O PODER DISCIPLINAR E O PODER SOBERANO}

Como ilustração inicial para dar margem ao debate acerca da noção de disciplina, consideremos o curso que Michel Foucault consagrou ao Collège de France, de 1973 a 1974, o qual chamou de O Poder Psiquiátrico. Na "Aula de 14 de novembro de 1973" (a segunda), ele trata de uma cena em que Philippe Pinel (1745-1826), considerado o pai da psiquiatria moderna, narra o caso de loucura do monarca Jorge III (soberano da Inglaterra no período de 1760 a 1820). O psiquiatra trata do caso do rei, que fora acometido por uma patologia e precisou ser isolado, quando de seu estado extremo de insanidade. Seu poder, força e "divindade" foramlhe suprimidos, e, não sendo mais considerado soberano, deveria ser dócil e submisso. (FOUCAULT, 2006, p. 26) Todavia, não se tratava apenas da súbita retirada dos poderes divinos do monarca, bem como de seu enclausuro, mas de submeter-lhe a um poder diferente do seu, que por sua vez o docilizou e o domesticou; incidindo diretamente sobre sua constituição somática, isto é, seu corpo. Um poder invisível, isto é, a disciplina, que segundo o filósofo francês,

É um poder anônimo, sem nome, sem rosto, é um poder que é repartido entre diferentes pessoas; é um poder, sobretudo, que se manifesta pela implacabilidade de um regulamento que nem sequer se formula, já que, no fundo, nada é dito, [...] Pois bem, no lugar desse poder decapitado e descoroado se instala um poder anônimo múltiplo, pálido, sem cor, que é no fundo o poder 
que chamarei de disciplina. (FOUCAULT, 2006, p. 27, 28, itálico nosso)

A cena lembrada por Foucault é infestada por uma decadente aura (o rei em sua queda doentia) e expõe os pontos centrais da disciplina, quais sejam, seu poder de submeter o sujeito alvo à docilidade, junto à mediação feita, neste caso, pelo discurso médico-psiquiátrico. A forma como ela se dá: fragmentada e discreta, mostrando que "é um poder que funciona em rede e cuja visibilidade encontra-se tão somente na docilidade e na submissão daqueles sobre quem, em silêncio, ela se exercer" (FOUCAULT, 2006, p. 28). Em outro clássico exemplo, a disciplina se configuraria como um tipo de poder que durante muito tempo existiu, e, de certo modo, ainda existe, se pensarmos no caso da instituição militar. Ora, a disciplina militar, há muito tempo, tem em sua essência o porte desses métodos para alcançar seu fim: o treinamento eficaz, a obediência, a correção e domesticação do corpo do soldado; visando produzilo e configurá-lo, além de incidir, obviamente, sobre sua constituição fisiológica.

Foucault, então, nos mostra que a disciplina existe há muito tempo (FOUCAULT, 1975, p. $217,218)$. Ela esteve alocada no seio do poder soberano, e, mesmo anteriormente ${ }^{1}$ ao século XVIII (momento clássico utilizado por Foucault para alusão à emergência das práticas disciplinares), fato que nos leva a crer que a mesma sempre existiu em grandes formações institucionais, no caso do exército, ou, em pequenas, como nos conventos e oficinas.

No entanto, o modelo disciplinar ganhou tanta importância, ou mesmo força, que "podese falar, em suma, da formação de uma sociedade disciplinar" (FOUCAULT, 1975, p. 217, 218), emergindo entre os séculos XVII/XVIII. Com o aparecimento de uma "arte do corpo", à qual Foucault diz ser o momento histórico possibilitador do aparecimento das disciplinas, formou-se uma política, ou melhor, uma anátomo-política, que deu conta do mesmo: o docilizou criticamente, na mesma medida em que entregou-lhe forças para que atuasse no âmbito econômico; assim, fabricou indivíduos dóceis, submissos e aptos ao trabalho. Em nosso arremate crítico, esta sociedade disciplinar é o típico modelo de formação social que se enquadra dentro dos limites do que podemos entender por capitalismo. Sabemos, hoje, que este último exige do indivíduo a praticidade e a versatilidade da mão-de-obra, bem como, sua qualificação e organização, em termos de tempo e espaço, ao qual se desenvolve. Logo, o capitalismo garante, ainda mais, o modelo disciplinar. Ademais, dentro das fronteiras do capital, a disciplina é como uma válvula por onde o corpo é "trabalhado detalhadamente", do mesmo modo, uma ignição que o controla, fazendo dele uma mensuração econômica que lide com a "eficácia de seus movimentos" e sua "organização interna”. (FOUCAULT, 1975, p. 217, 218).

É comum ouvirmos dizer que a soberania (modelo clássico de "representação" de poder) se configura pelo extenso uso da força, mais certeiramente, pela "visibilidade" das práticas punitivas. O rei, ou a representação deste poder régio, abusaria de seu poder para impor determinada sanção a determinado desvio, dentro dos limites de onde se estabelece sua "jurisdição”, ou, seu território. No início da obra Surveiller et Punir, Foucault (1975, p. 9-12) expõe, por exemplo, os arquivos do caso de Damiens: condenado em 2 de março de 1757. O mesmo fora exposto ao mais terrível dos suplícios para que ficasse claro o poder da mão do rei. Percebemos, com isto, que a soberania se trata de um poder de "subtração", de "tomada" ou "apropriação”, seja da vida, como de bens. Na contrapartida, em La volonté de savoir (1976), e mesmo

\footnotetext{
1 A partir deste momento haverá uma "mudança de tensão" que alocará a disciplina de forma prioritária à soberania; lembremos que o modelo soberano entrará em declínio, dada a expansão mercantil, ocasionando o advento do capitalismo como novo modelo econômico.
} 
ainda em Surveiller et Punir, Michel Foucault expressa seu total "desapego" (FOUCAULT, 2015b, p. 89-100) a esta forma enviesada de se pensar o poder. Enviesada, pois, com ela, tendese a admitir que o poder é tido como algo que "se tem", personificando-o em figuras como a do Estado, ou do Rei; assim, traduzindo-se como "substância", ou, como "bem" que se adquire. Além do mais, seria um viés por onde o poder estaria "pobre em seus recursos, econômico em seus procedimentos, monótono nas táticas que utiliza, incapaz de invenção e como que condenado a se repetir sempre. [...] é um poder que só teria a potência do "não" (FOUCAULT, 2015b, p. 93).

O francês propõe um novo como, ou, uma nova forma de se pensar o poder, através de uma tecnologia que extravasou os limiares da história, de forma totalmente heterogênea, e que funciona "não pelo direito, mas pela técnica, não pela lei, mas pela normalização, não pelo castigo, mas pelo controle, e que se exerce em níveis e formas que extravasam o Estado e seus aparelhos" (FOUCAULT, 2015b, p. 98). Um funcionamento que se dá através da cultura, costumes, instituição e indivíduos, não sendo necessariamente negativo ou positivo, mas "produtivo" (FERDER, 2011, p. 56).

Em linhas gerais, o poder não seria apenas repressão, não nos diz respeito apenas ao poder herdado, de direito originário, ou, como fonte de poder político; ou, ainda, levando-se em conta a teoria marxista do poder: poder como dominação (luta de classes). A filosofia política de Foucault busca o "partir de baixo" (FOUCAULT, 1997, p. 27), através da hipótese da luta, ou tensão, que se ampara nas observações, por exemplo, que Nietzsche outrora fez. É a ideia de que o poder se perfaz através das capilaridades mais distantes dos macroaspectos ideológicos que o tornam, ou tendem a torná-lo, um "universal". Foucault se posiciona sempre em um ângulo crítico e de suspeita, opondo-se, por exemplo, no caso, a Hobbes, cânone das teorias jusnaturalistas, que tanto influenciou as diversas teorias políticas com seu modelo do leviatã, no qual o espectro da monarquia reaparece toda vez que se discute esse assunto. A questão do poder seria muito menos sobre a problemática da guerra, do medo, ou da legitimação de leis, via arsenal jurídico, e, muito mais, um “enfrentamento belicoso de forças", este é o locus do poder em Foucault. (BERT, 2013, p. 103, 104)

Para que fiquem mais claras as oposições, dentro da obra de Foucault, a respeito da soberania e da disciplina, na "Aula de 21 de novembro de 1973", do curso O Poder Psiquiátrico, Foucault examina mais profundamente estes dois poderes, diferenciando-os; faremos a exposição esquemática de suas características. No caso do poder soberano, elas são quatro: 1 - A assimetria: na qual o poder soberano se apropria dos bens, armas, coragem e tempo dos súditos, mas em uma relação de gastos, na qual há um retorno do mesmo para fins como: celebrações, festas, ou, os chamados "serviços religiosos"; estes fins nem sempre figuram na mesma medida de sua apropriação (ocorrem "desníveis"). 2 - A anterioridade fundadora: ou seja, a ideia de que a soberania sempre é herdada, seja por direito divino, conquista, ou, ainda pela vitória do soberano no front da batalha; este fator anterior sempre se atualiza, dadas as novas vitórias e celebrações. 3 - A não-isotopia: seria a ideia de que não há um sistema único ou uma classificação exaustiva/planificada, isto é, a soberania dá lugar às diferenciações: do rei ao suserano; do pai à família; do professor ao aluno; do mestre ao aprendiz. 4 - O sujeito múltiplo: seria a elementaridade, não do sujeito individual, mas da massa populacional, como um todo. Para a soberania, não haveria uma coincidência "entre o sujeito de uma relação de soberania e a singularidade somática”. Neste aspecto, o corpo assujeitado não se converte em indivíduo. A soberania não dispõe dos indivíduos um a um, mas marca-os, suplicia-os, usa-os; não há a conversão do 
“múltiplo” para o "individual”. (FOUCAULT, 2006, p. 53-57; CASTRO, 2009, p. 406)

Por conseguinte, ocorre a oposição, ponto a ponto, do poder disciplinar junto ao poder soberano: 1 - A disciplina não tenta (nem quer) ser assimétrica. Não há uma relação "coletadespesa" (FOUCAULT, 2006, p. 57), como ocorre na soberania. Se trata de uma apropriação total, ou, que tende ser exaustiva: do corpo, do tempo, do comportamento, dos gestos. 2 - A disciplina não precisa dos arranjos cerimoniais, das comemorações, etc. Sob o jugo disciplinar, ninguém está à disposição de outrem; sempre há uma inteira vigilância, um perpétuo controle e uma continuidade. Há uma configuração "ótima"/ "terminal”, em detrimento ao poder soberano que sugere um acontecimento, e na qual se observa uma anterioridade, seja por divindade, herança ou conquista. Resumindo, a disciplina "funcionará sozinha". (FOUCAULT, 2006, p. 59) 3 - A disciplina e seus mecanismos tendem à isotopia, que remonta à diversas situações: os indivíduos, à ela expostos, possuem seus lugares, hierarquias, funções e valores, muito bem delimitados e reticulados; não há descontinuidades em seus deslocamentos; ocorre uma regularidade básica: por concurso, exame, antiguidade, etc.; seus sistemas funcionam todos como em uma engrenagem onde tudo está associado, ou, entrelaçado; sua exaustiva classificação produz classe até ao que antes era inclassificável, como no caso da loucura. (CASTRO, 2009, p. 405) 4 - Última oposição: a disciplina é individualizante. Ora, a soberania apenas marca e fragmenta os sujeitos (como já visto, por meios de punição), já a disciplina "assujeita-os", sua finalidade é esta, "o mecanismo de disciplina abrocha [épingle] a função-sujeito à singularidade somática”. (CASTRO, 2009, p. 406)

Houveram também razões para que ocorresse a "não-vigência"2 da teoria jurídica da soberania no arrolar histórico, principalmente do século XVIII para cá. Foucault as expõe, alguns anos após o curso O Poder Psiquiátrico, na "Aula de 21 de janeiro de 1976", do curso Il faut défendre la société. Destacamos a seguinte proposição:

A soberania é a teoria que vai do sujeito para o sujeito, que estabelece a relação política do sujeito com o sujeito. [...] a teoria da soberania confere, no início, uma multiplicidade de poderes que não são poderes no sentido político do termo, mas são capacidades, possibilidades, potências, e que ela só pode constituí-los como poderes, no sentido político do termo, com a condição de ter, entrementes, estabelecido, entre as possibilidades e os poderes, um momento de unidade fundamental e fundadora, que é a unidade do poder. [...] é dessa unidade do poder que vão derivar as diferentes formas, os aspectos, mecanismos e instituições de poder. [...] a teoria da soberania mostra, tenta mostrar, como um grande poder pode constituir-se não exatamente segundo a lei, mas segundo uma certa legitimidade fundamental, mais fundamental do que todas as leis, que é um tipo de lei geral de todas as leis e pode permitir às diferentes leis funcionarem como leis. (FOUCAULT, 1997, p. 37, 38)

A soberania é a tríplice formação entre sujeito, poder e lei; que fundamenta e serve de pedra-de-toque para as análises modernas, "freudo-marxistas", as quais a utilizam para análise de noções como a de repressão. Por outro lado, segue a disciplina, paralelamente, agindo pela via da domesticação do corpo, da vigilância, controle do tempo e produção de subjetividade.

\footnotetext{
2 Concordamos com Foucault no quesito que diz respeito à não unicidade de presença das diversas teorias jurídicas, principalmente as contemporâneas, mas seria inegável admitir que noções jurídico-discursivas não continuam existindo fortemente no dia-a-dia dos sujeitos, principalmente no Brasil, onde sempre, ou quase sempre, acompanham-se tendências exteriores, ao invés da ressignificação das já existentes, ou, no limite, "criação" de normas e códigos adequados à nossa realidade. Foucault, quando debate estas questões, ao nosso ver, oferece um novo olhar para um novo tipo de configuração política e de poder.
} 
As diferenças nos modos de exercício do poder, acima citadas, têm relação - no caso do poder disciplinar - com o fato de que, para Michel Foucault, o poder é produtivo, principalmente no tangente ao processo pós-industrial.

Ainda no curso de 76, o francês elenca cinco precauções metodológicas acerca de seus estudos sobre poder. A questão por trás desta forma de estudo ampara-se no quesito: "quais são as regras de direito de que lançam mão as relações de poder para produzir discursos de verdade? Ou ainda: qual é esse tipo de poder capaz de produzir discursos de verdade que são, numa sociedade como a nossa, dotados de efeitos tão potentes?" 3 .

O poder está entrelaçado pelo saber de tal maneira que tem por compromisso formar discursos de verdade. Discursos estes que têm relação com a proveniência histórica ao qual os sujeitos estão submersos. As precauções metodológicas, por exemplo, não tardam a aparecer sob a alcunha do direito e do campo judiciário. São elas: $1^{\text {a }}$ - O poder não será analisado a partir de seu eixo central e em suas regulamentações ou formas legítimas. É um estudo que parte do que está ao redor, nas "suas extremidades", assim como no organismo humano, onde há artérias e vênulas que se ramificam do centro às periferias do corpo. Este estudo sobre o poder vai lá onde o mesmo se torna capilar que, entre outras palavras, quer dizer: lá onde o poder está mais localizado, mais regionalizado, além das regras de direito que tendem a organizá-lo ao redor de mecanismos jurídicos. 2a - Não tratar do poder ao nível da intenção ou da decisão, afinal, isso levaria às questões quem é detentor do poder? Onde está o poder? Ora, de maneira bem simples, trata-se de estudá-lo por sua "forma externa", lá no ponto onde "ele se implanta e produz efeitos reais". Efeitos estes que, literalmente, "sujeitam os corpos, dirigem os gestos, regem os comportamentos". $3^{\text {a }}$ - O poder não é apenas "poder de dominação", não é maciço, nem homogêneo. O poder funciona em redes, cadeias; ele circula, transita; não é uma "ferramenta aplicável". Nessa mecânica, inclusive, quem é submetido a ele também possui meios para submeter outros, e assim por diante. $4^{\text {a }}$ - Visto todos nós sermos, de certo modo, detentores deste poder, ele ao mesmo tempo não é uma matéria "dedutível", onde "partiria do centro" e "tentaria ver até onde ele se prolonga por baixo". O poder partiria de algo como uma ascese, do menor ao maior fator possível, daquele que já é infinitesimal, indo ao vultoso. Desta maneira, entendemos como o mesmo é encoberto por mecanismos maiores, que o escondem em seus princípios "mais gerais" de funcionamento. $5^{\mathrm{a}}$ - Tende-se a percebê-lo como parte de ideologias, no entanto, Foucault declara: "no ponto em que terminam as redes de poder, o que se forma, não acho que sejam ideologias. [...] São instrumentos efetivos de formação e acúmulo de saber, são métodos de observação [...], são aparelhos de verificação". (FOUCAULT, 1997, p. 24-30)

Estas preocupações metodológicas conferiram, ao nosso ver, a "maleabilidade" do poder, isto é, seu caráter não "enrijecido", e, sim, "volátil”, já que não opera mais através de velhas noções e categorias ontológicas. Não obstante, Foucault influenciou e ainda influencia diversas faculdades de conhecimento, que não somente a filosofia, por estender suas noções justamente para além do âmbito restritivo da filosofia política clássica. A exemplo, veremos na próxima seção, como há um âmbito "real” da discussão que Foucault propõe acerca da disciplinarização dos corpos, oferecida por ele mesmo no âmbito da análise da estrutura do panóptico, a prisãoinvenção de Jeremy Bentham.

\footnotetext{
3 “... quelles sont les règles de droit que les relations de pouvoir mettent en œuvre pour produire des discours de vérité? Ou encore: quel est donc ce type de pouvoir qui est susceptible de produire des discours de vérité qui sont, dans une société comme la nôtre, dotés d'effets si puissants ?’ (FOUCAULT, 1997, p. 21, tradução nossa)
} 


\section{PANÓPTICO: ESPAÇO DISCIPLINAR DE OLHAR E VIGILÂNCIA}

A invenção do panóptico, promovida por volta do final do século XVIII pelo importante filósofo e reformador social inglês Jeremy Bentham (1748-1832), é tomada por Michel Foucault como um marco na mudança dos regimes de penalidades e a emergência de novas formas de poder e controle. Situando Bentham na era denominada "ortopedia social", classificada também como "sociedade disciplinar", o filósofo francês aponta-o como um dos principais teóricos representativos deste modelo, também chamado de "sociedade da vigilância". ${ }^{4}$

Segundo Foucault, o panóptico consiste não somente em um aparelho de controle e vigilância a serviço de um novo tipo de poder, mas como dispositivo de produção, extração e organização de saber. Em Surveiller et punir (1975), por exemplo, Foucault aponta à analogia entre o panóptico e o zoológico, enquanto dispositivos especializados na classificação (das espécies, dos indivíduos, das doenças, etc.) e na observação individualizante.

Bentham não diz se se inspirou, no seu projeto, no zoológico que Le Vau construíra em Versalhes: primeiro zoológico cujos elementos não estão, como tradicionalmente, disseminados em um parque. [...] Mas achamos no programa do Panóptico, o cuidado análogo da observação individualizante, da caracterização e da classificação, da organização analítica do espaço. O panóptico é um zoológico real; o animal é substituído pelo homem [...] Fora essa diferença, o Panóptico faz também o trabalho de naturalista. Permite estabelecer as diferenças: nos doentes, observar os sintomas de cada um [...] nos operários, anotar as aptidões de cada um, comparar o tempo que levam para executar uma obra e, se são pagos por dia, em consequência, calcular o seu salário. (FOUCAULT, 1975, p. 204, 205)

Verifica-se que o panóptico não é mera criação arquitetônica de um novo modelo de prisão, mas o princípio de ordenação de um novo tipo de poder - o poder disciplinar - que se institui juntamente com novos saberes que irão se fundar na norma, definida como a nova lei da sociedade moderna - a norma é fundada basicamente nas ciências da vida, nas novas ciências médicas - e não mais no princípio de soberania, de acordo com o modelo jurídico-político de poder. (FOUCAULT, 1977, p. 39, 40)

O panóptico figura não somente como uma mera construção arquitetônica. Ele é também um "princípio" de organização espacial, uma constante, um dispositivo multifacetado de vigilância que assegurava o exercício do poder em seu máximo desempenho, da forma mais leve e sútil, sempre poupando excessos desnecessários. Além de tudo, poder-se-ia traduzir o panóptico, também, como uma forma de economia do Estado, uma vez que este último utilizava tal mecanismo de modo a empregar poucos funcionários no exercício da vigilância de muitos. (BENTHAM, 2008, p. 20, 21; FOUCAULT, 1975, p. 201-206; MILLER, 2008, p. 89) Esta engenhosa invenção não delimita apenas um espaço físico, mas sim um dispositivo disciplinar, que segundo Foucault, serve para sujeitar os indivíduos ao controle e à vigilância ininterruptas.

O panóptico possuía objetivos moralizadores: como era aberto para visitações, o dispositivo causava nos presos a vergonha da exposição pública e mostrava aos espectadores visitantes o impacto da punição sobre aqueles corpos, pois expunha uma vitrine de vigilância, solidão e punição, que os presos recebiam por seus atos. Os visitantes viam os apenados do centro da

4 “[...] Foi ele que programou, definiu e descreveu da maneira mais precisa as formas de poder em que vivemos e que apresentou um maravilhoso e célebre pequeno modelo desta sociedade da ortopedia generalizada: o famoso Panopticon." (FOUCAULT, 2002, p. 86) 
torre de vigilância que serviam, então, de "exemplo" do resultado da quebra das leis. Esta estrutura também deixava visível ao espectador as virtudes econômicas e racionais desta máquina de poder, visto que o visitante (estando na posição de trabalho do vigilante) tomava noção da economia e velocidade as quais o panóptico oferecia para aquela função. (MILLER, 2008, p. 96)

Doravante, como princípio, via de regra e dispositivo, a estrutura panóptica também era aplicável a todo espaço onde se desejava efetuar o controle massivo: na fábrica, para impulsionar e organizar a produção, tornando-a eficaz; na escola, para controlar e disciplinar os(as) alunos(as); ou, no hospital, dividindo os leitos por categorias de enfermidade, níveis de contágio, etc., este dispositivo "multifacetado" serviu muito bem ao que se propôs. Ainda hoje observamos seus resquícios: desde sua fundação, com o passar do tempo, a máquina benthamiana se adaptou, ganhando novas formas e faces. Podemos pensar, por exemplo, nas inúmeras vias públicas, de grandes e médias cidades, que são controladas por câmeras e outros dispositivos eletrônicos, com a finalidade de preservar a segurança pública. Ora, preserva-se a segurança e a integridade pública, mas, junto a isto, efetua-se a disciplinarização mútua, já que os(as) indivíduos(as) têm noção de que são vigiados(as) e que não devem exceder os limites legais. Em supermercados, outro grande exemplo, controla-se muito melhor os eventuais pequenos furtos; utiliza-se, para tal, muitas câmeras, onde, de uma central de controle, alguém vigia o espaço. A união de princípios físico/estruturais, moralizadores e econômicos deram à invenção de Bentham sua devida notoriedade. Em uma época na qual os valores punitivos ainda carregavam consigo traços advindos do poder soberano e toda sua espetacularização, o panóptico benthamiano trouxe consigo o oposto destes conceitos. Com suas características inovadoras, abriu espaço ao novo modelo punitivo dos séculos que viriam: a de uma multiplicidade de funções.

\section{DELEUZE E AS SOCIEDADES DE CONTROLE}

Em um breve texto, intitulado "Post-scriptum sobre as sociedades de controle", escrito para o jornal L'Autre, em $1^{\circ}$ de maio de 1990, Gilles Deleuze, também filósofo francês, e amigo de Foucault, delimita características da "sociedade de controle" que julgou "superar", ou, substituir, as sociedades disciplinares descritas por seu contemporâneo, Michel Foucault. Assim como a soberania se tornou um modelo ultrapassado, a disciplina teve sua obsolescência, segundo o filósofo francês parisiense (DELEUZE, 2013, p. 223, 224). É importante lembrarmos que a passagem histórica ao modelo disciplinar não excluiu, de fato, um certo modus operandi da soberania nas sociedades modernas. Como já explicado alguns momentos atrás, a soberania continua sendo "eficaz", se pensarmos seus resquícios no chamado modelo "jurídico-político" atual. Em níveis proporcionais, as disciplinas atuam muito mais na esfera social, todavia, sempre adjuntas, ou paralelas, ao exercício do poder soberano. Sanções, leis, limites territoriais, todos ainda se configuram como traços advindos da soberania, muito embora dividirem espaço, em proporção menor, com a disciplina. Desta maneira, torna-se difícil interpretar a passagem destes momentos históricos pela via da "superação", quando, na verdade, o que há é uma mudança de foco ou, em nossas palavras, um "paralelismo", e ainda, como comenta Yuk Hui (2015, p. 74), uma "continuidade".

Todavia, segundo Deleuze, da mesma maneira como aconteceu a "superação", da soberania à disciplina, seriam então as sociedades de controle que dariam continuidade e "superariam" as 
sociedades disciplinares foucaultianas. Mas o que isto quer dizer? "Controle”, aqui, refere-se à maneira como a vida tem-se resumido às frequentes atividades, seccionadas e pormenorizadas dentro do conjunto neoliberal capitalista, estancadas em um discurso no qual o que impera é o interesse individual, o consumo e a produtividade: "[...] é o nome que Burroughs propõe para designar o novo monstro, e que Foucault reconhece como nosso futuro próximo" (DELEUZE, 2013, p. 224). É uma passagem que se dá na mudança de foco entre o enclausuro diretamente pensado através de artifícios físicos e de ambientes fechados (prisões, fábricas, conventos, hospitais, quartéis), típicos das sociedades disciplinares, para, então, a maleabilidade e difusão, ou, "modulação", do novo sistema capitalista empresarial.

Para esclarecermos esta dissonância e termos a emergência genealógica do termo controle, basta entendermos como se deu a esfera tríplice de atuação, da chamada por Foucault, "governamentalidade" (gouvernementalitê). Segundo ele, este modus de operacionalização estatal envolve três aspectos primordiais: governo, população e economia política, acontecendo marcadamente a partir do século XVIII. Sendo-nos mais precisos, a governamentalidade trata do conjunto de instituições, análises, operações, que "tem por alvo principal a população, por principal forma de saber a economia política e por instrumento técnico essencial os dispositivos de segurança" (FOUCAULT, 2004b, p. 111). À luz do que expomos até agora, pedimos atenção à última palavra citada por Foucault, "segurança". Se lembrarmos do início do curso de 78 , frisemos que o filósofo inicia seus debates convidando o público a entender o que foram os "mecanismos de segurança" presentes nas sociedades que se pautaram neste modelo. (FOUCAULT, 2004b, p. 10). Tais mecanismos giram ao entorno problemático da acessibilidade e da circulação de bens, ou seja, do "controle" de tudo o que acontecia na cidade. Por "controle", então, temos que entender, não a atividade de privação ou domínio, mas a manutenção do nicho, isto é, de certos locais dentro de uma cidade. E, não apenas o nicho, mas principalmente, as estatísticas diversas: de roubos, de crimes, de epidemias e quaisquer outros desvios normativos, já que estes são considerados como peças inextinguíveis, no entanto, passíveis de controle. Em suma, os Estados governamentalizados são Estados administrativos, e, com isso, Estados que controlam seus níveis de "anormalidades" sociais. 5 Estados "controladores".

Sabemos que a organização dos principais cursos de Foucault a respeito deste tema se dera muito posteriormente à sua morte e, inclusive, da de Deleuze (principalmente nos casos dos cursos de 1978 e 1979). Percebemos que os dois tratam de eventos em comum, utilizando léxicos diferentes, ou, que se entrecruzam e se somam; interseccionando informações. Quando Deleuze se refere às sociedades disciplinares, as alude através da ideia de confinamento. No nível institucional, a disciplina realmente confina seus indivíduos, prendendo-os à lógica da fábrica, ou, em seu clássico exemplo, ao modus da prisão. Por outro lado, a lógica presente nas sociedades de controle seria a da empresa, a qual, segundo Deleuze, "introduz o tempo todo uma rivalidade inexpiável como sã emulação [...] que contrapõe os indivíduos entre si..." (DELEUZE, 2013, p. 225). É a partir disso que Deleuze afirma haver uma crise que marca a passagem do disciplinar ao controle, na qual, mais especificamente, "Os confinamentos são moldes, distintas moldagens, mas os controles são uma modulação, como uma moldagem autodeformante [...]" (DELEUZE, 2013, p. 225). O ponto fulcral a respeito das sociedades de controle deleuzianas finca-se então na noção de modulação, pouco trabalhada pelo mesmo. As sociedades de controle seriam ambientes de modulação, isto é, de criação de espaços para os indi-

\footnotetext{
${ }^{5}$ Para mais esclarecimentos, evitando nos estender muito, indicamos a leitura da primeira e quarta aula do curso Segurança, território, população, de Foucault.
} 
víduos: "[...] como se ele ou ela tivesse a liberdade de emaranhar e criar, enquanto a sua produção, bem como os seus fins, seguem a lógica das forças intangíveis” (HUI, 2015, p. 75, tradução nossa).

Nos textos de Foucault, diríamos que aquela lógica "mercadológica", de autoempresariamento, típica das sociedades capitalistas neoliberais, encontra-se muito precisamente nas quatro últimas aulas de seu curso dado ao Collège de France, em 1979, chamado de Nascimento da biopolítica. (FOUCAULT, 2004a). Quando Foucault retoma a questão do homo oeconomicus, justamente buscou marcar a eclosão de um sujeito totalmente voltado ao próprio interesse, ao consumo, ao empresariamento de si próprio; fazendo de seu tempo, bem como de sua vida pessoal, algo que deva ser produtivo sempre. Da mesma forma Deleuze expõe sua concepção quando menciona que nas sociedades de controle "nunca se termina nada, a empresa, a formação, o serviço sendo os estados metaestáveis e coexistentes de uma mesma modulação, como que um deformador universal." (DELEUZE, 2013, p. 226).

A grande diferença entre os dois é que Deleuze pré-dispõe sua análise à clara imersão das sociedades neoliberais de controle (empresariais) aos diversos artifícios tecnológicos que nela estão presentes. ${ }^{6}$ Em claro exemplo, basta lembrarmos que Foucault não viveu afinco o advento da internet, já Deleuze presenciou pelo menos o início da emergência da mesma. Isto fica claro quando ele remente, em seu texto, referenciações a, por exemplo, Paul Virilio, autor contemporâneo que problematizou, em diversas de suas obras, o avanço das tecnologias de comunicação (DELEUZE, 2013, p. 224). Em estudos recentes, por exemplo, um dos grupos de pesquisa do Laboratório de Tecnologias Livres (LabLivre), da Universidade Federal do $\mathrm{ABC}(\mathrm{UFABC})$ afirma, utilizando do léxico deleuziano, que

\begin{abstract}
Nas sociedades de controle, conectadas por tecnologias cibernéticas, principalmente pelas redes digitais, emergiram as plataformas de relacionamento online como intermediárias de uma série de interesses, afetos e desejos das pessoas. A modulação pode ser apresentada como uma das principais operações que ocorrem nestas plataformas. Modular comportamentos e opiniões é conduzi-los conforme os dispositivos algorítmicos que gerenciam os interesses de influenciadores e influenciados. (SOUZA, AVELINO e DA SILVEIRA, 2018, p. 9)
\end{abstract}

Se as fábricas ou regimes disciplinares são moldes "estáticos"; as empresas, o controle e as modulações, seriam "maleáveis" e, de certo modo, "líquidas" (como diria Bauman). Ilustrando: em substituição à "escola tradicional" e de formação estática, entra em cena a formação permanente; onde o que impera é a noção de um "controle contínuo" e de qualificação ininterrupta. Isso quer dizer que sociedade de controle e sua tipologia capitalista/neoliberal é constante quanto à autoprodução. Deleuze (2013, p. 226) mesmo chega a considerar a dualidade entre individualização/massificação dos poderes disciplinares atentando à questão do poder pastoral, presente na obra de Michel Foucault. Deve-se, aqui, levar em conta próprio aspecto de controle presente em um poder que, ao mesmo tempo, individualiza e controla a população como um todo, isto é, segundo Foucault, o velho e conhecido ditado "todos e cada um" (omnes et singulatim). (FOUCAULT, 1994) ${ }^{7}$

\footnotetext{
${ }^{6}$ Indicamos ao leitor o trabalho de Allex Williams (2015), "Control Societies and Platform Logic", e de Yuk Hui (2015), "Modulation after Control", para o cotejo e aprofundamento destas noções. No Brasil, um trabalho recente e de muita qualidade foi realizado pelo Laboratório de Tecnologias Livres (LabLivre), da Universidade Federal do ABC (UFABC), citado na bibliografia e no corpo deste texto.

${ }^{7}$ Indicamos, metodologicamente, ao nosso leitor, a leitura desta conferência, qual seja, Omnes et singulatim: vers une critique
} 
A forma como Deleuze explica este fenômeno nos é muito cara: ele expõe a divergência entre controle e disciplina através da metáfora consecutiva cifra e registro, ou, cifra e assinatura/ matrícula, já interagindo com as novas formas tecnológicas atuais; "a assinatura indica o indivíduo, e o número de matrícula [...] indica sua posição numa massa", em oposição à cifra que torna os indivíduos " "dividuais', divisíveis, e as massas tornaram-se amostras, dados, mercados ou 'bancos"' (DELEUZE, 2013, p. 226); assim, mais uma vez, conscientemente, subverte o texto de Foucault para fazer interagir seu próprio projeto, atribuindo que o dinheiro é a forma capital que distancia as duas sociedades: enquanto na disciplinar a moeda é física, estática, moldada a ouro; na sociedade de controle, o dinheiro refere-se à especulação, "a trocas flutuantes" (DELEUZE, 2013, p. 226), posicionamento que aponta a crítica direta ao regime do capitalismo neoliberal corrente no início dos anos 1990.

Sendo-nos mais certeiros, vejamos como Deleuze direciona seu pensamento:

As conquistas de mercado se fazem por tomada de controle e não mais por formação de disciplina, por fixação de cotações mais do que por redução de custos, por transformação do produto mais do que por especialização da produção. [...] O serviço de vendas tornou-se o centro ou a "alma" da empresa". (DELEUZE, 2013, p. 228)

E, é claro, estas palavras soariam como profecias (se pudéssemos voltar ao passado para ratificá-las): nunca antes fora vista tamanha exposição de nossa subjetividade aos mecanismos de marketing atuais que estão potencializados com os chamados big-datas diversos. $\mathrm{Na}$ internet, por exemplo, somos bombardeados por ofertas massivas de produtos, em uma extensa rede de interações com nossas pesquisas pessoais, rastros e caminhos, deixados nos espaços wmw. Alguns dos críticos e estudiosos contemporâneos de Gilles Deleuze intensificam ainda mais estes estudos “para-além” de Michel Foucault. É o caso do sociólogo italiano Maurizio Lazzarato quando comenta que

Com a desterritorialização neoliberal, não surgiu nenhuma nova produção de subjetividade. Ao mesmo tempo, o neoliberalismo destruiu as relações sociais anteriores e suas formas de subjetivação (subjetivação operária, comunista, social-democrata ou subjetividade nacional, burguesa, etc.) A promoção neoliberal do empreendedor, com a qual Foucault associa a mobilização subjetivada requerida e seu gerenciamento, em todas as formas de atividade econômica, não oferece solução ao problema. [...] O capital sempre precisou de um território que não o do mercado ou da empresa, assim como precisou de uma subjetividade que não aquela do empresário; pois, apesar de o empresário, a empresa e o mercado fazerem a economia, elas desfazem a sociedade. (LAZZARATO, 2014, p. 14)

Vemos, assim, uma intensificação das medidas neoliberais de constituição de sujeito que, na verdade, entregam ao indivíduo contemporâneo uma crise; não de constituição, mas de desconstituição, de desterritorialização, de desafirmação de identidade e particularidade perante a massificação contemporânea incutida em vieses mercadológicos. Deleuze (2013) salienta e nos oferece instrumental de análise para atentarmos o quanto as sociedades de controle estão ligadas às crises das disciplinas (sem, todavia, as encerrar), na medida em que as modulações, ágeis e velozes - dos controles em meio aberto - são da ordem de fluxos centrífugos e centrí-

de la raison politique", presente no compêndio Dits et Écrits. Ela funciona como uma introdução à temática tratada no curso de 78, por Foucault, isto é, a governamentalidade. 
petos das disciplinas liberadas do confinamento, bem como, dos muros de espaços disciplinares fechados. Ora, com efeito, os fluxos liberados são sobrecodificados, organizados e extratificados em segmentações do capital neoliberal. Eles operam por meio de racionalidades empresariais de compra e venda de serviços, seja sob a insígnia de uma marca, ou sob o gás do marketing, enquanto aquilo que é alvo da publicidade do mass media; atuam também na produção de investimentos das lógicas empreendedoras de existências e das práticas da economia política do capitalismo financeiro internacional. Ainda vale mencionar que a dívida infinita e impagável também é um mecanismo da sociedade de controle, sendo um processo de subjetivação contemporâneo na mundialização, amplamente materializado a partir da segunda metade do século XX, seguindo até hoje. Na sociedade de controle ninguém pode parar de estudar, trabalhar, pagar contas virtuais em cartões de créditos, leasings, prestações de casa própria, de carro, etc. Nunca se termina nada. Sempre se está em dívida com algo. Sentimos que devemos e nos cobramos; cobramos os outros e somos cobrados full time.

A passagem entre os modelos de sociedade, sob a ótica deleuziana, acompanha também o rastro das mudanças nas formas de trabalho modernas. Enquanto no taylorismo os trabalhadores seguem "códigos estritos" e "bem-definidas instruções" dentro das fábricas, a partir de 1980, segundo Yuk Hui (2015, p. 75), esta realidade muda, dando lugar ao "controle por modulação" (o pesquisador utiliza a definição do sociólogo francês Philippe Zarifian) que entrega ao trabalhador uma maior "liberdade" para gestão de seu próprio tempo de trabalho. O conceito de modulação, sem dúvidas, possui destaque e atravessa, senão toda, boa parte da obra de Deleuze, possuindo diversos links e vínculos com as obras de outros autores ${ }^{8}$. Mas, quando Deleuze trabalha com este léxico, quer se referir à tese de Gilbert Simondon, L'individuation à la lumière des notions de forme et d'information (A individuação à luz das noções de forma e de informação, 1964), que é resistente à ideia de moldagem. Esta última influenciou o pensamento do ocidente, retomando a relação entre forma e matéria advindas do pensamento aristotélico. Logo, quando Simondon trabalha este termo, está operando uma crítica ao hilomorfismo, isto é, à teoria aristotélica que enquadra as noções supracitadas em "categorias absolutamente distintas", às quais "nós podemos derivar a essência do ser de qualquer entidade". (HUI, 2015, p. 76, tradução nossa) A crítica de Deleuze, então, pode ser lida também como uma crítica ao tradicionalismo metafísico, encrustado no pensamento ocidental. Pela mesma via, segue Foucault, principalmente em seus trabalhos referentes ao momento "arqueológico", se pensarmos sob pontos de vistas bem delimitados.

\section{CONCLUSÃo}

Vimos, durante nosso trajeto, a exposição de dois importantes modos de enxergar as sociedades modernas, que se entrecruzam sob certos aspectos, e, em outros, se distanciam, afirmando suas próprias nuances, e, nos dando suas próprias contribuições. Michel Foucault e Gilles Deleuze desempenharam papel crucial para a identificação dos modos de ser modernos; imersos, nos casos vistos acima, em regimes de controle, e disciplinamento do tempo, dos

\footnotetext{
${ }^{8}$ Yuk Hui (2015, p. 76) enumera algumas passagens: em Diferença e Repetição (1968), Deleuze, muito provavelmente, referese a este conceito interligando-o à obra e à modulação no sentido de seu contemporâneo, Gilbert Simondon, opondo a ideia de modulação como característica da experiência em uma crítica a filosofia crítica de Kant, em que a experiência é subentendida por meio de categorias e de intuições sensíveis. Em Mil Platôs (1980), novamente, Deleuze retoma a ideia de modulação por meio de sua crítica do hilomorfismo, bem como, em sua monografia dobre Leibniz.
} 
atos, em suma, da vida. Podemos afirmar tal validade, acrescentando apenas que tais traços tomaram rumos diferentes, de nação a nação. Principalmente nas chamadas "democracias liberais", onde, dentre elas, podemos nos enquadrar. O capital tomou ritmos absurdamente avassaladores em nosso país, principalmente desde sua transfiguração em capital neoliberal, a partir de meados dos anos 1990.

As constantes crises do neoliberalismo, além-Brasil, nos mostraram os perigos de tal modelo, inclusive, também, seu eventual desmoronamento massivo, a partir da crise de 2008 . O mundo especula, cada vez mais; com isso, as desigualdades também se tornaram especulativas, se averiguarmos quem hoje domina e tem em mãos o capital. Resta-nos a tarefa de reavaliação de nossos modos de ser, em tempos os quais o consumo exacerbado tomou conta da vida.

Concluindo, disciplina e controle entraram em confluência e imanência, ou seja, em correlação de forças entrecruzadas, na sociedade contemporânea, figurando então, como duas racionalidades interligadas, às quais sustentam o capitalismo mundial integrado, o neoliberalismo em condução na gestão dos corpos e da vida: em meio aberto, no caso do controle, e revezando meios abertos e fechados, nas situações disciplinares, tais como, as panópticas. Portanto, vale destacar a relevância em investigar mais as relações entre disciplina e controle nos trabalhos de Foucault e Deleuze, através de conversações múltiplas e ressonâncias recíprocas.

\section{REFERÊNCIAS}

BENTHAM, J. O panóptico. Belo Horizonte: Autêntica Editora, 2008.

BERT, J.-F. Pensar com Michel Foucault. São Paulo: Parábola, 2013.

CASTRO, E. Vocabulário de Michel Foucault: um percurso pelos seus temas, conceitos e autores. $1^{\mathrm{a}}$. ed. Belo Horizonte: Autêntica, 2009.

DELEUZE, G. Conversações (1972-1990). Tradução de Peter Pál Pelbart. $3^{a}$. ed. São Paulo: Editora 34, 2013.

FERDER, E. K. "Power/Knowledge". In: TAYLOR, D. (Ed.) Michel Foucault: key concepts. Stocksfield UK: Acumen Publishing Limited, 2011.

FOUCAULT, M. Surveiller et punir: naissance de la prison. Paris: Éditions Gallimard, 1975. FOUCAULT, M. O nascimento da clínica. Rio de Janeiro: Forense-Universitária, 1977.

Il faut défendre la société: cours au Collège de France (1975-1976). Paris: Gallimard/Seuil, v. Hautes Études, 1997.

2002.

A Verdade e as Formas Jurídicas. 3ª Edição. ed. Rio de Janeiro: NAU Editora,

Naissance de la biopolitique: cours au Collège de France (1978-1979). Paris: Gallimard/Seuil, v. Hautes Études, 2004a.

Sécurité, territoire, population: cours au Collège de France (1977-1978). Paris: Ehhes/Gallimard/Seuil, v. Hautes Études, 2004b.

O Poder Psiquiátrico: curso dado ao Collège de France (1973-1974). São Paulo: Martins Fontes, 2006.

2015.

Microfísica do Poder. Tradução de Roberto Machado. Rio de Janeiro: Paz e Terra, $2015 b$.

História da Sexualidade 1: A Vontade de Saber. 2a . ed. São Paulo: Paz \& Terra, . “Omnes et singulatim': vers une critique de la raison politique.” In. Dits et Écrits. 
t. IV. Paris: Gallimard. 1994.

HUI, Yuk. "Modulation after Control" In. New Formations, Numbers 84/85, Autumn 2015, pp. 74-91(18). DOI: https://doi.org/10.3898/NewF:84/85.04.2015

LAZZARATO, M. Signos, máquinas, subjetividades = Signes, machines, subjectivities. Tradução de Paulo Domenech Oneto. $1^{\mathrm{a}}$ Edição. ed. São Paulo: Edições Sesc São Paulo, 2014.

MILLER, J.-A. "A máquina panóptica de Jeremy Bentham." In: BENTHAM, J. O Panóptico. Belo Horizonte: Autêntica Editora, 2008.

MUCHAIL, S. T. Foucault, simplesmente. São Paulo: Edições Loyola, 2004.

RABINOW, P.; DREYFUS, H. L. Michel Foucault, uma trajetória filosófica: para além do estruturalismo e da hermenêutica. Tradução de Vera Portocarrero. Rio de Janeiro: Forense Universitária, 1995.

SOUZA, J.; AVELINO, R.; DA SILVEIRA, A. (Orgs.) A sociedade de controle: manipulação e modulação nas redes digitais. 1ª ed. São Paulo: Hedra, 2018.

WILLIAMS, Alex. "Control Societies and Platform Logic" In. New Formations, Numbers 84/85, Autumn 2015, pp. 209-227(19). 